\title{
Understanding Treatment Preferences in Patients with Moderate to Severe Plaque Psoriasis in the USA: Results from a Cross-Sectional Patient Survey
}

\author{
Joe Gorelick (D) - David Shrom - Kiran Sikand - Lisa Renda • \\ Russel Burge · Christine Dworkin • Craig Krebsbach • Ripsi P. Patel • \\ Chitra Karki · David Rosmarin
}

Received: August 22, 2019 / Published online: October 19, 2019

(C) The Author(s) 2019

\section{ABSTRACT}

Introduction: The goal of psoriasis (PsO) treatment is to improve quality of life by lessening the extent and severity of the disease. Traditional systemic drugs and biologic agents are used for the treatment of moderate to severe $\mathrm{PsO}$ and recent research emphasizes understanding patient goals and preferences for treatment, to improve overall outcomes.

Methods: An online survey was administered to collect data from 500 adult patients with moderate to severe PsO in the USA. Patients were required to have current or previous systemic therapy use and were excluded if aged 75 or older. Data on demographics, disease burden,

Enhanced Digital Features To view enhanced digital features for this article go to https://doi.org/10.6084/ m9.figshare.9923687.

J. Gorelick ( $\square)$

California Skin Institute, San Jose, CA, USA

e-mail: jgorelick1@me.com

D. Shrom · K. Sikand · L. Renda · R. Burge

Eli Lilly and Company, Indianapolis, IN, USA

R. Burge

University of Cincinnati, Cincinnati, OH, USA

C. Dworkin - C. Krebsbach · R. P. Patel · C. Karki

Ipsos Insights LLC, New York, NY, USA

D. Rosmarin

Tufts Medical Center, Boston, MA, USA treatment use, and patients' treatment goals and expectations were collected. Descriptive and multivariate analyses examined the factors that predict treatment goals. Subgroup analyses were performed for age, gender, severity, comorbid psoriatic arthritis (PsA), location of $\mathrm{PsO}$, and biologic experience. All analyses were conducted using SAS v9.4 and R v3.4.

Results: Of the 500 adult patients included, $71.6 \%$ reported moderate PsO. Patients had a mean (SD) score of 62.4 (23.0) for skin pain, 60.0 (26.3) for fatigue, and 6.6 (2.1) for itch on a scale of $0-100,0-100$, and 0-10 respectively. Mean (SD) score for quality of life (QoL), assessed using Dermatology Life Quality Index (DLQI), was 18.3 (7.3), with more than 90\% having moderate/very large/extremely large effect on life. The majority of patients considered "keeping skin clear for 2-3 years" (94\%), "overall relief of symptoms" (93.8\%), and effective in clearing certain areas" (92.2\%) as important attributes of a systemic treatment. Overall, patients expected 50\% clear skin in about 2 weeks and completely clear skin in about 4 weeks.

Conclusions: Overall, in this study with more than $70 \%$ of patients with moderate disease, patients reported high burden of disease and impact on QoL. This study demonstrates the importance of considering patient perspectives in treatment decisions that are critical for optimizing patient outcomes.

Funding: Eli Lilly and Company. 
Keywords: Patient-reported outcomes; Plaque psoriasis; Rapid response; Real-world analysis; Treatment expectations; Treatment goals

\section{INTRODUCTION}

A chronic, immune-mediated skin disease, plaque psoriasis (PsO) is the most common form of psoriasis and can result in raised, red, silver, or flaky patches on the skin. Affecting $1-3 \%$ of the world's population, $\mathrm{PsO}$ is associated with significant disease burden, including poor quality of life (QoL), increased disability, social stigmatization, and decreased emotional and physical well-being [1-3]. In addition, PsO is linked to co-morbidities including psoriatic arthritis (PsA), obesity, diabetes mellitus, and cardiovascular disease [1-3]. Long-term management of $\mathrm{PsO}$ is essential for improving quality of life and lessening the burden of comorbid conditions. While mild disease is often controlled with topical agents, systemic therapy is often used to treat patients with moderate to severe disease, defined as involvement of 3-10 and greater than 10 percent of the body surface area (BSA), respectively [3]. Traditional systemic drugs include methotrexate, cyclosporine, and acitretin. More recently, a multitude of biologic therapies have been approved for PsO. Biologic and non-biologic therapies vary widely in their benefit/risk profiles, as well as in other aspects related to convenience.

Evidence is now accumulating that, to optimize patient outcomes, there should be a shared decision-making process between patients and physicians [1]. Patients are heterogenous in terms of how PsO manifests, how severe it is, how much it impacts their lives, and what their specific treatment goals may be. To this end, American Academy of Dermatology (AAD) guidelines recommend tailoring treatment choices to the individual patient [4]. Ultimately, understanding patient attitudes and preferences for treatment attributes can lead to greater treatment satisfaction, treatment adherence and compliance, and better long-term outcomes [5-8].
For patients with moderate to severe psoriasis, data is accumulating on treatment preferences and expectations. The largest and most complete data sets from the German Psoriasis (PsoBest) and Swiss Dermatology Network of Targeted Therapies (SDNTT) registries highlight the value of obtaining completely clear skin and rapid onset for patients $[9,10]$. Because treatment decisions or changes are likely to occur when patients do not have adequate disease control, the objectives of this study are to expand on previous findings and provide clinicians insights into the treatment preferences and disease burden of patients who are still impacted by $\mathrm{PsO}$ and are dissatisfied with their current therapy.

\section{METHODS}

\section{Study Design and Participants}

This study was executed as a cross-sectional online quantitative survey targeting adult patients $(n=500)$ with moderate to severe PsO in the USA. Patient inclusion criteria were adult patients with moderate to severe PsO (selfassessed based on BSA $\geq 3$ ), current or previous use of systemic therapy within the past 12 months (non-biologic and biologic systemic therapies), and a score of 7-10 (on a 10-point scale) for at least one of the following questions: Agreement on "I want a medication that clears my skin more effectively" or "I miss out on aspects of my life because of psoriasis". Any respondent aged 75 or older or who was working for a pharmaceutical, health insurance, research, or advertising company was excluded as there may be self-presentation effects that could alter the interview answers. Medical professionals were also excluded as the intent was to obtain purely a patient perspective. Furthermore, any respondent unwilling or unable to provide informed consent was excluded from this study.

The study (Protocol \#18-045418) was approved by Pearl Institutional Review Board (IRB) and met the standards of both Food and Drug Administration (FDA) 21 Council of Federal Regulations (CFR) 56.104 and Department 
of Health and Human Services (DHHS) 45 CFR 46.101 regulations. Informed consent was obtained from all participants prior to participating in the study. This study was conducted in full conformance with the Guidelines for Good Pharmacoepidemiology Practices (GPP) published by the International Society of Pharmacoepidemiology (ISPE) and the laws and regulations of the country in which the research was conducted.

The survey was executed between December 2018 and January 2019. Potential respondents were recruited from various internet patient panels to participate in the cross-sectional online survey, approximately $20 \mathrm{~min}$ in duration. The interview request included a statement of informed consent and a set of screening questions based on the inclusion/exclusion criteria. The respondent could choose to quit the survey at any point without penalty. Upon completion of the survey, they were compensated through their panel in the form of "points", equivalent to \$10-15 USD, which can be redeemed for goods or the participant would be entered into a raffle.

\section{Survey and Measures}

Development of the survey content was facilitated by initial qualitative interviews conducted among 12 patients with moderate to severe $\mathrm{PsO}$, approximately $45 \mathrm{~min}$ in length in September 2018. These interviews were exploratory teleinterviews in the USA which evaluated how PsO affects patients' lives, and what great medication results look like from a patient's perspective.

The final survey collected demographic information (including age, gender, race, gender, ethnicity, height/weight, employment status, and smoking history), disease characteristics, treatment use, and QoL. Disease characteristics included self-assessed BSA involvement, self-assessed severity, psoriasis location, and patient global assessment of genital PsO.

Self-assessed BSA involvement was measured by the number of palms that covered the patches on the body, 3-10 representing moderate disease severity and more than 10 classified as severe disease [11]. Overall disease severity was also assessed using a self-reported rating scale of 0 (no PsO) to 100 (severe PsO) and genital PsO severity was assessed on a scale of 0 (clear, no $\mathrm{PsO}$ ) to 5 (severe, the worse PsO). Psoriasis Skin Appearance Bothersomeness (PSAB), a validated tool on a scale of $0-10$ in which in 0 is "not at all bothered" and 10 is "extremely bothered", was used to determine the current extent of symptoms bothering the patients. Each of the symptoms (redness/discoloration, thickness, and scaling/flaking) was queried separately on a scale of $0-10$. The three-item scores were summed for a total score ranging from 0 to 30 with higher scores indicating more bothersomeness due to skin appearance [12]. Current symptom assessments of skin pain (in the past week, on the visual analogue scale (VAS) $0-100$, 0 being none and 100 being worst), itch (in the past $24 \mathrm{~h}$ was assessed using Itch Numeric Rating Scale (Itch NRS) 0-10, 0 being no itch and 10 being worst imaginable itch), and fatigue (in the past week, on VAS 0-100, 0 being none and 100 being worst) were also collected [13-16]. Patients' current use of non-biologic (methotrexate, cyclosporine) and biologic systemic agents (tumor necrosis factor (TNFs), interleukin (IL)-17s, IL-12/23 s, IL-23, apremilast) was also collected.

Quality of life was captured using Dermatology Life Quality Index (DLQI, 0-30), with a recall period of 1 week. DLQI is a highly cited validated 10-question assessment of the effect of the patient's dermatologic condition on QoL, with the following categories for scores: 0-1 (none), 2-5 (small), 6-10 (moderate), 11-20 (very large), and 21-30 (extremely large) for impact on QoL [17].

\section{Patients' Goals for New Treatment}

The importance of treatment attributes was captured on a scale of $0-10$, where 0 is not at all important and 10 is extremely important. Attributes assessed included probability of side effects, overall effectiveness (achieving clear skin), rapidity of response, overall relief of symptoms (e.g., itching and skin pain), 
sustained response for longer time periods (2-3 years), and effectiveness in clearing certain hard-to-treat areas (i.e., nail, scalp, genitals, palms, and soles). A set of novel questions were designed to understand patient expectations for onset of efficacy as a treatment attribute. Specifically, patients were asked to report how many days they expect to see a 50\% improvement or $100 \%$ improvement in their PsO, respectively.

\section{Statistical Analysis}

Descriptive analyses were conducted to describe the patient sample with respect to patient demographics, disease characteristics, treatment use, and treatment goals/expectations. Frequencies and percentages were reported for categorical outcomes and means, standard deviations (SD), medians and first and third quartiles were reported for continuous outcomes. Descriptive statistics were used to inform the exact variables in the multivariable logistic regression model.

A multivariate logistic regression model was conducted to examine the impact of different factors on patient preferences towards treatment goals. The dependent variable (patient preference towards each of the treatment goals) was defined as those who had high preference (a score of at least 7 on a $0-10$ scale, 0 being low importance and 10 being high importance) vs. those who had low preference to the treatment goals. Age, gender, disease duration, and biologic experience were included as a priori independent covariates in the models. The final models were assessed for parsimony using the Akaike information criterion (AIC), area under the curve (AUC), and a pseudo $r^{2}$. Independent variables (IVs) that did not add enough information to the final models were considered for removal to keep the number of IVs minimal while still ensuring a strong model fit. The final model was presented as parameter estimates with standard errors and $Z$ scores. Odds ratios $(\mathrm{OR})$ and confidence intervals $(\mathrm{CI})$ were also presented. The overall model $X^{2}$ was presented along with the AUC and final pseudo $r^{2}$ values. Models were run for the following dependent (outcome) variables: "rapid response", "keeping skin clear for 2-3 years", "overall relief of symptoms", and "effective in clearing in certain areas like nail, scalp, genitals, palms, and soles", after adjusting for the a priori covariates mentioned above.

In addition to the multivariate analyses, descriptive analyses on different subgroups of interest were also performed for gender (male vs. female), age groups (18-30, 31-40, 41-50. and $51+$ ), disease severity (moderate vs. severe), comorbid PsA (PsO only vs. PsO + PsA), location of $\mathrm{PsO}$ (trunk, extremities, palms/soles, nails, scalp, genitals, face, ears, and other) and biologic experience (biologic-naïve vs. biologicexperienced) to assess if the treatment goals and expectations were different between these subgroups.

All analyses were conducted using statistical analysis software (SAS, Cary, NC) v9.4 or R v3.4. On the basis of the programming of the survey all relevant questions required a response, though options for "unknown" or "decline to answer" (or similar values as appropriate for the specific question) were available. As a result, missing data was kept to a minimum. Missing responses were reported as such. For instances in which missing data were observed for an explanatory variable, the explanatory variable was coded in such a way as to combine with the separate category of "unknown/missing." Missing data for an outcome variable was addressed using case-wise deletion; no imputation strategy was used.

\section{RESULTS}

\section{Patient Population and Clinical Characteristics}

Of the approximately 14,000 patients with $\mathrm{PsO}$ that were invited to participate in the quantitative study, $18.5 \%(n=2596)$ responded to the invitation. Of those 2596 patients, $67.4 \%$ $(n=1749)$ did not meet the inclusion criteria, $12.2 \%(n=316)$ started the survey but did not complete it, 31 (1.2\%) qualified for the survey but responded after the maximum quota of 500 participants was met, and $19.3 \%(n=500)$ met 


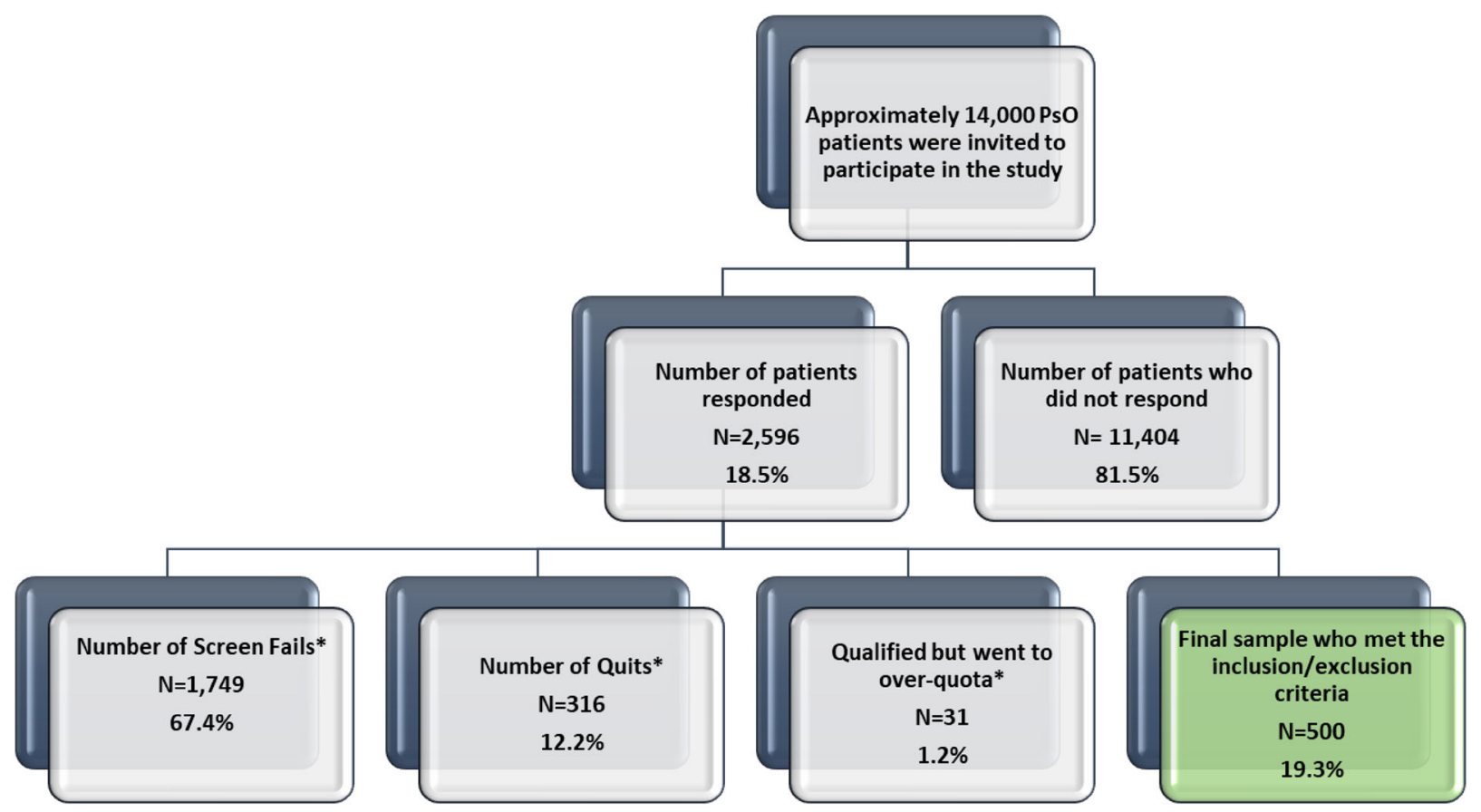

Fig. 1 Patient recruitment flow chart. ${ }^{*}$ “Screen fails” defined as those who did not meet the inclusion criteria. "Quits" defined as those who started the survey but failed

the inclusion and exclusion criteria and were included in the final sample (Fig. 1).

All demographic characteristics of this sample are shown in Table 1 . The 500 adult US patients included $231(46.2 \%)$ men and 269 $(53.8 \%)$ women with mean age of $39.9(12.0)$ years. Most patients were white (77.4\%), employed full time (72.8\% full time) and had prescription drug insurance/coverage through a current or former employer or union (58.2\%). Less than one-third $(26.2 \%)$ of the patients were "current smokers" and almost half of the patients were "never smokers" (46.4\%). Mean body mass index (BMI) was 27.5 (7.1), with more than half of them (56\%) in the overweight and obese categories.

\section{Disease Burden}

When assessing clinical characteristics, as displayed in Table 2, patients had a mean (SD) disease duration of 8.7 (8.8) years and, according to the BSA definition outlined above in the "Survey and Measures" section, $71.6 \%$ of patients had moderate PsO (BSA 3-10) and to complete it. "Qualified but went to over-quota” defined as those who responded after we met the quota of $n=500$

$28.4 \%$ of patients with severe PsO (BSA $>10$ ). A higher proportion of patients reported $\mathrm{PsO}$ in hard-to-treat areas like scalp (65.6\%), face $(52.8 \%)$, nails $(22 \%)$, and genitals $(25.2 \%)$. In terms of current symptom assessment, the mean score for skin pain in the past week on a scale of $0-100$ was reported to be 62.4 (23.0), mean itch in the past $24 \mathrm{~h}$ was 6.6 (2.1) on a scale $0-10$, and mean score for fatigue in the past week on a scale of $0-100$ was reported to be 60.0 (26.3). Mean scores for PSAB in these patients was $23.5(5.5)$, on a scale of $0-30$, with higher scores indicating greater severity and annoyance for the patients. About 90\% of the patients with genital $\mathrm{PsO}$ reported a score of at least 3 for severity of genital psoriasis on a scale of $0-5$, where 0 is clear/no PsO and 5 is severe/worst PsO has ever been. Mean score for QoL, assessed using DLQI, was 18.3 (7.3), with most patients (more than 90\%) having moderate or very large or extremely large effect on life as shown below (Table 2). Almost 70\% of the patients were currently on a biologic, with the majority of them on their first biologic. 
Table 1 Patient demographics $(n=500)$

\begin{tabular}{|c|c|}
\hline & $\begin{array}{l}\text { Number } \\
\text { (percentage) }\end{array}$ \\
\hline \multicolumn{2}{|l|}{ Age in years } \\
\hline Mean (SD) & $39.9(12.0)$ \\
\hline Median (Q1, Q3) & $39(30,48)$ \\
\hline \multicolumn{2}{|l|}{ Gender } \\
\hline Male & $231(46.2)$ \\
\hline Female & $269(53.8)$ \\
\hline \multicolumn{2}{|l|}{ Race/ethnicity ${ }^{\mathrm{a}}$} \\
\hline Caucasian/White & $387(77.4)$ \\
\hline African American/Black & $59(11.8)$ \\
\hline Hispanic/Latino & $79(15.8)$ \\
\hline Asian & $15(3)$ \\
\hline Native American/Alaskan Native & $7(1.4)$ \\
\hline Pacific Islander & $1(0.2)$ \\
\hline Other/unknown & $6(1.2)$ \\
\hline \multicolumn{2}{|l|}{ Employment status } \\
\hline Working full-time & $364(72.8)$ \\
\hline Working part-time & $37(7.4)$ \\
\hline Homemaker, no outside employment & $23(4.6)$ \\
\hline Student & $12(2.4)$ \\
\hline Unemployed & $15(3)$ \\
\hline Retired & $23(4.6)$ \\
\hline Disabled & $26(5.2)$ \\
\hline \multicolumn{2}{|l|}{ Insurance coverage $^{a}$} \\
\hline $\begin{array}{l}\text { Prescription drug insurance/coverage } \\
\text { through a current or former employer } \\
\text { or union }\end{array}$ & $291(58.2)$ \\
\hline $\begin{array}{l}\text { Prescription drug insurance/coverage } \\
\text { purchased directly from an insurance } \\
\text { company }\end{array}$ & $128(25.6)$ \\
\hline Medicare Part D & $38(7.6)$ \\
\hline $\begin{array}{l}\text { Medicaid, Medical Assistance, or any } \\
\text { kind of government-assistance plan for } \\
\text { those with low income or a disability }\end{array}$ & $75(15)$ \\
\hline
\end{tabular}

Table 1 continued

\begin{tabular}{|c|c|}
\hline & $\begin{array}{l}\begin{array}{l}\text { Number } \\
\text { (percentage) }\end{array}\end{array}$ \\
\hline $\begin{array}{l}\text { TRICARE or other military health } \\
\text { care }\end{array}$ & $6(1.2)$ \\
\hline $\begin{array}{l}\text { Veteran Affairs (VA; including those } \\
\text { who have ever used/enrolled for VA } \\
\text { health care) }\end{array}$ & $9(1.8)$ \\
\hline Indian Health Service & $3(0.6)$ \\
\hline None & $29(5.8)$ \\
\hline Other & $8(1.6)$ \\
\hline \multicolumn{2}{|l|}{ Smoking history } \\
\hline $\begin{array}{l}\text { Current smoker [Yes, I currently } \\
\text { smoke] }\end{array}$ & $131(26.2)$ \\
\hline $\begin{array}{l}\text { Past smoker [Yes, I smoked regularly in } \\
\text { the past, but do not currently OR Yes, } \\
\text { I smoked occasionally in the past, but } \\
\text { do not currently] }\end{array}$ & $137(27.4)$ \\
\hline $\begin{array}{l}\text { Never smoker [No, I have never } \\
\text { smoked] }\end{array}$ & $232(46.4)$ \\
\hline \multicolumn{2}{|l|}{ Weight [pounds] } \\
\hline Mean (SD) & $178.4(48.9)$ \\
\hline Median (Q1, Q3) & $173(145,200)$ \\
\hline \multicolumn{2}{|l|}{ BMI, calculated ${ }^{\mathrm{b}}$} \\
\hline Mean (SD) & $27.5(7.1)$ \\
\hline Median (Q1, Q3) & $\begin{array}{l}25.8(22.9 \\
30.5)\end{array}$ \\
\hline Underweight $(<18.5)$ & $14(2.8)$ \\
\hline Normal (18.5-24.9) & $206(41.2)$ \\
\hline Overweight $(25.0,29.9)$ & $144(28.8)$ \\
\hline Obese $(\geq 30)$ & $136(27.2)$ \\
\hline
\end{tabular}

All variables are presented as $n$ (\%) unless otherwise noted ${ }^{a}$ Not mutually exclusive

b Body mass index (BMI) = weight in pounds/(height in inches) $)^{2} \times 703$ 
Table 2 Clinical characteristics, treatment use, and QoL measures $(n=500)$

\begin{tabular}{|c|c|}
\hline & $\begin{array}{l}\text { Number } \\
\text { (percentage) }\end{array}$ \\
\hline \multicolumn{2}{|l|}{ Clinical characteristics } \\
\hline \multicolumn{2}{|l|}{ Disease severity } \\
\hline $\begin{array}{l}\text { Moderate (body surface area [BSA] } \\
3-10)\end{array}$ & $358(71.6)$ \\
\hline $\begin{array}{l}\text { Severe (body surface area } \\
[\mathrm{BSA}]>10)\end{array}$ & $142(28.4)$ \\
\hline \multicolumn{2}{|c|}{$\mathrm{PsO}$ severity [range $0-100](0$, no $\mathrm{PsO} ; 100$, severe $\mathrm{PsO})$} \\
\hline Mean (SD) & $75.3(16.1)$ \\
\hline Median (Q1, Q3) & $80(70,90)$ \\
\hline \multicolumn{2}{|c|}{$\begin{array}{l}\text { Disease duration (time from diagnosis to date of survey } \\
\text { completion), years }\end{array}$} \\
\hline Mean (SD) & $8.7(8.8)$ \\
\hline Median (Q1, Q3) & $5(3,10)$ \\
\hline \multicolumn{2}{|l|}{ Current $\mathrm{PsO}$ location ${ }^{\mathrm{a}}$} \\
\hline Trunk & $236(47.2)$ \\
\hline Extremities & $318(63.6)$ \\
\hline Palms/soles & $212(42.4)$ \\
\hline Nails & $110(22)$ \\
\hline Scalp & $328(65.6)$ \\
\hline Genitals & $126(25.2)$ \\
\hline Face & $264(52.8)$ \\
\hline Ears & $202(40.4)$ \\
\hline Other & $42(8.4)$ \\
\hline \multicolumn{2}{|l|}{ Severity of genital $\mathrm{PsO}$ [range $0-5$ ] } \\
\hline$n$ & $126(0.25)$ \\
\hline 0 (Clear; no $\mathrm{PsO})$ & $1(0.79)$ \\
\hline 1 & $5(3.97)$ \\
\hline 2 & $6(4.76)$ \\
\hline 3 & $35(27.78)$ \\
\hline 4 & $46(36.51)$ \\
\hline $\begin{array}{l}5 \text { (severe; the worst your } \mathrm{PsO} \text { has } \\
\text { ever been) }\end{array}$ & 33 (26.19) \\
\hline
\end{tabular}

Table 2 continued

\begin{tabular}{ll}
\hline & $\begin{array}{l}\text { Number } \\
\text { (percentage) }\end{array}$ \\
\hline Treatment use & \\
Therapy class & \\
Light and laser therapy & $90(18)$ \\
Corticosteroids & $147(29.4)$ \\
Topical therapies & $172(34.4)$ \\
Non-biologic systemics & \\
Non-steroidal anti-inflammatory & $88(17.6)$ \\
drugs & \\
Biologics &
\end{tabular}

Biologic experience (including the current biologic)

$$
\begin{array}{ll}
0 & 152(30.4) \\
1 & 294(58.8) \\
2 & 35(7) \\
3+ & 19(3.8)
\end{array}
$$

Patient-reported outcomes

Current symptom assessment

Skin pain (in the past week) [range 0-100 (0, none; 100 , worst)]

$$
\begin{array}{ll}
\text { Mean }(\mathrm{SD}) & 62.4(23.0) \\
\text { Median (Q1, Q3) } & 67(50,79.3)
\end{array}
$$

Itch NRS (in the past $24 \mathrm{~h}$ ) [range $0-10(0$, no itch; 10 , worst imaginable itch)]

$$
\begin{array}{ll}
\text { Mean }(S D) & 6.6(2.1) \\
\text { Median (Q1, Q3) } & 7(6,8) \\
7+ & 275(55)
\end{array}
$$

Fatigue (in the past week) [range $0-100(0$, none; 10 , worst)]

$$
\begin{array}{ll}
\text { Mean }(\mathrm{SD}) & 60.0(26.3) \\
\text { Median (Q1, Q3) } & 66(46,79) \\
7+ & 210(42)
\end{array}
$$

DLQ1 score, calculated $(n=463)^{\mathrm{c}}$

Mean (SD)

$18.3(7.3)$ 
Table 2 continued

\begin{tabular}{ll}
\hline & $\begin{array}{l}\text { Number } \\
\text { (percentage) }\end{array}$ \\
\hline Median (Q1, Q3) & $19(13,24)$ \\
DLQI, categorical & \\
$0-1$ (no effect) & $4(0.86)$ \\
$2-5$ (small effect) & $24(5.18)$ \\
$6-10$ (moderate effect) & $51(11.02)$ \\
$11-20$ (very large effect) & $179(38.66)$ \\
$21-30$ (extremely large effect) & $205(44.28)$ \\
\hline
\end{tabular}

All variables are presented as $n$ (\%) unless otherwise noted $P_{s} O$ psoriasis, QoL quality of life

a Not mutually exclusive

b $n=37$ dropped because of 2 or more "no" responses per Dermatology Life Quality Index (DLQI) scoring instructions

c Non-biologic systemics include cyclosporine, methotrexate, soriatane, sulfasalazine

d Biologics include Otezla, Amevive, Cimzia, Costenyx, Enbrel, Humira, Ilumya, Remicade, Siliq, Simponi, Stelara, Taltz, and Tremfya

\section{Treatment Goals and Treatment Change}

We found that patients generally valued effectiveness more than the side effects of a therapy when we queried how much they valued various treatment attributes when considering treatment change; with $94 \%$ of the patients rating a score of at least 7 for "high probability of achieving clear skin" and $82.6 \%$ rating a score of at least 7 for "low probability of side effects", on a scale of $0-10$ (where 0 is not at all important and 10 is extremely important) (Fig. 2). Additionally, the vast majority of patients (at least 90\%) gave high importance (score of at least 7) to all efficacy attributes, namely rapid response, keeping skin clear for 2-3 years, overall relief of symptoms, and effective in clearing skin in certain areas (Fig. 2). When patients' expectations of time to see a treatment response were examined, overall patients expected to see $50 \%$ clear skin in about 2 weeks (mean 16.4 days) and achieve completely clear skin in about 4 weeks (mean 33.8 days).

We further explored the expectations for rapid response across different subgroups. Patient expectations for a new systemic therapy to deliver $50 \%$ improvement varied across different subgroups, compared to the overall results (mean (SD) of 16.4 (19.2) days to achieve $50 \%$ improvement in symptoms and know that medication is working). Across all age groups examined (18-30, 31-40, 41-50, 51+), younger age groups (18-30 and 31-40) expected to achieve $50 \%$ improvement from a new systemic therapy sooner than the older age groups: mean (SD) of 14.8 (13.2) and 15.3 (18.8) days, respectively. Among the disease severity subgroups, patients with moderate disease (BSA 3-10) expected the new systemic therapy to show 50\% improvement sooner than the patients with severe disease $(\mathrm{BSA}>10)$ (mean (SD) 15.5 (18.1) days vs. 18.5 (21.8) days, respectively). Similar findings were seen among the patients with PsO only compared to patients with PsO and PsA (mean (SD) 14.5 (16.2) days vs. 18.3 (21.9) days, respectively). Among the biologic experience subgroups, biologic-experienced patients expected the new systemic therapy to show 50\% improvement sooner than the biologic-naïve patients (mean (SD) 15.4 (17.4) days vs. 18.6 (22.8) days, respectively) (Fig. 3a).

Among all the location subgroups analyzed (trunk, extremities, palms/soles, nails, scalp, genitals, face, ears, and other), patients with genital PsO expected the lowest number of days for a new systemic therapy to show 50\% improvement (mean (SD) 13.3 (11.3) days). Interestingly, patients with $\mathrm{PsO}$ on nails and scalp reported higher number of days for expectations from a new systemic therapy to show 50\% improvement (mean (SD) 18.4 (22.3) and 17.8 (21.8) days, respectively) (Fig. 3b).

Multivariate models were completed to evaluate treatment goals. However, as a result of the high percentage of patients indicating a strong preference of 7 or higher (above $90 \%$ in all categories accept "low probability of side effects"), models were deemed largely inappropriate. The age of the patient was the only factor which was identified as having a significant 


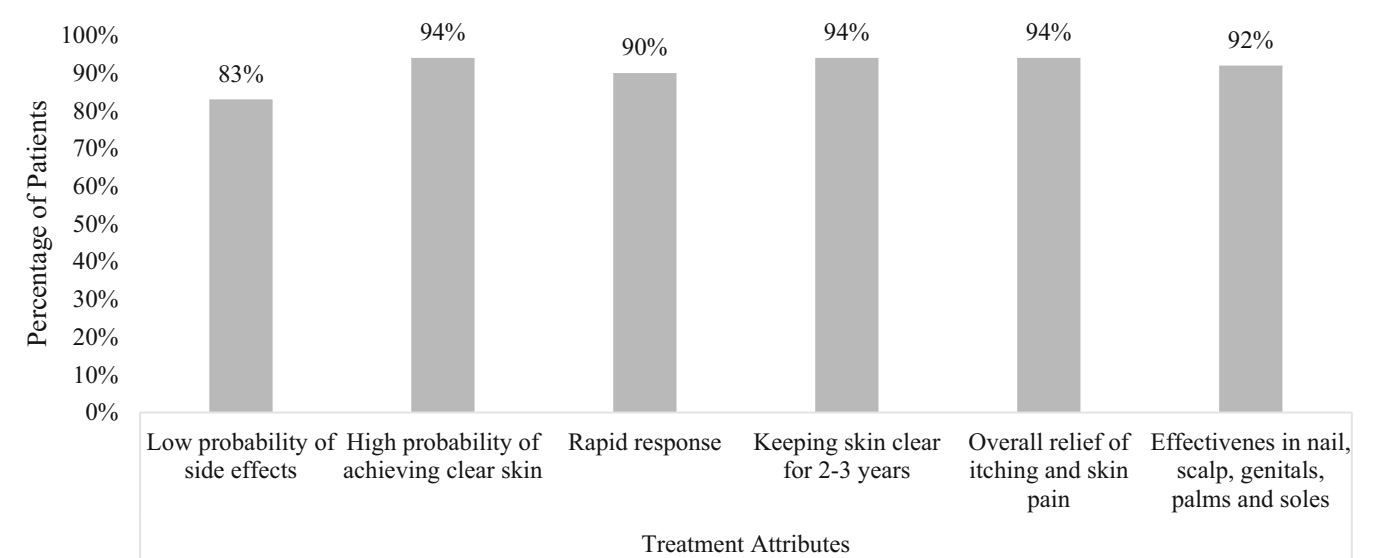

Fig. 2 Percentage of patients indicating high importance for treatment attributes (score of at least 7, on a scale of 1-10 where 1 is not at all important and 10 is extremely important) $(n=500)$

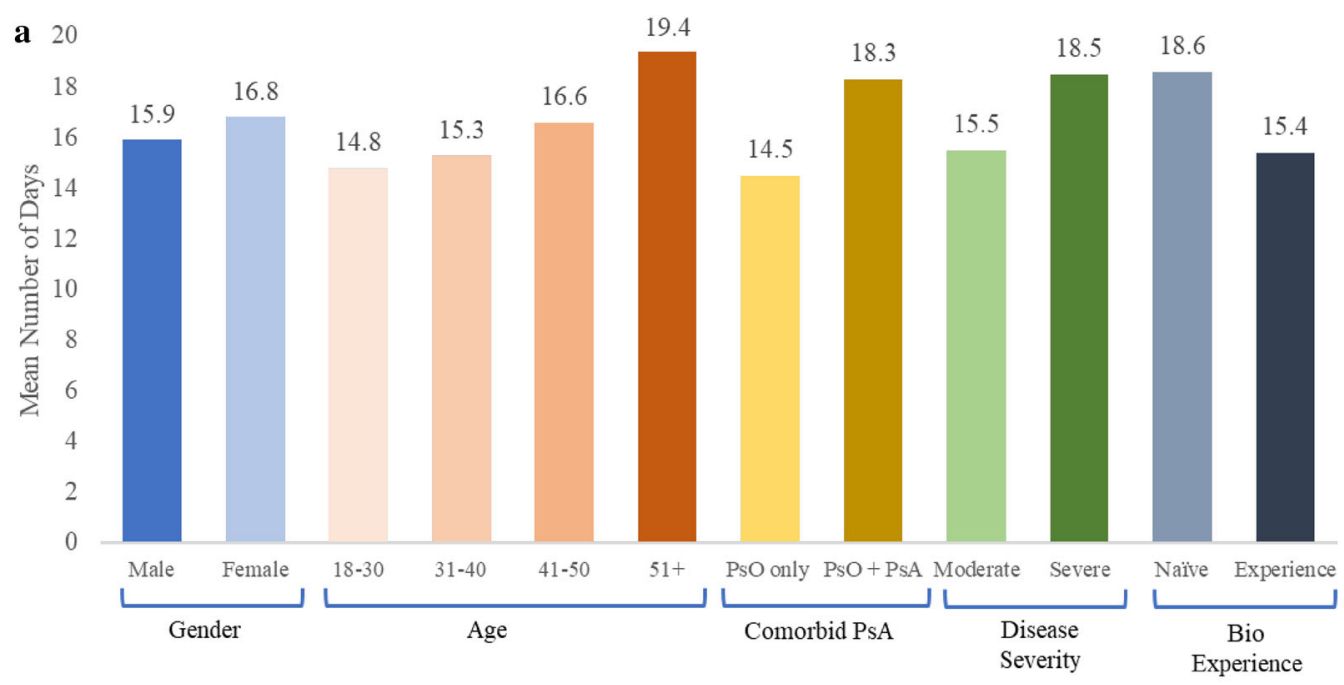

b 25

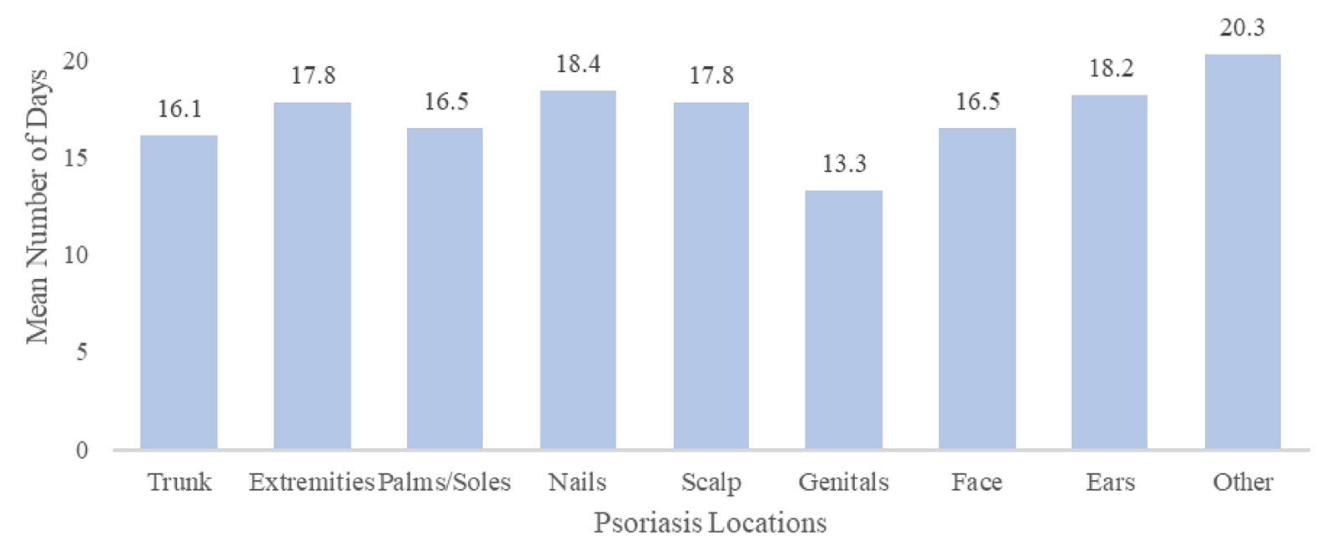

Fig. 3 Patient expectation of a systemic treatment for achieving 50\% clear skin a among different subgroups $(n=500)$ and b based on $\mathrm{PsO}$ location (not mutually exclusive) $(n=500)$ 
association with preference for the treatment attributes of rapid response, keeping skin clear for 2-3 years, and overall relief of symptoms, and effectiveness of clearing certain areas.

\section{DISCUSSION}

Recent research and guidelines indicate that considering the patient perspective in treatment decisions is essential to improve treatment satisfaction, adherence, and to achieve optimal patient outcomes [5-8]. In this study, our goal was to provide clinicians with important information on the patient perspective when facing a treatment change decision. To this end, our study included patients who were not satisfied with the current level of disease control and wanted to consider a new treatment option, and we reported not only the treatment preferences and expectations for these patients but also the current burden of their symptoms and impact on their QoL.

Overall, the patient population in this study was similar to those in previous studies examining patient preferences and treatment goals in terms of disease severity and impact on QoL $[2,18]$. The patients with psoriasis in this study were slightly younger (39.9 years), had a shorter mean disease duration (8.7 years), slightly lower BMI $\left(27.5 \mathrm{~kg} / \mathrm{m}^{2}\right)$, and the majority were female (54\%) when compared to patients from a study using the PsoBest registry (47.2 years, 18.3 years, $28.4 \mathrm{~kg} / \mathrm{m}^{2}$, and $40.40 \%$, respectively) [5], which is a German PsO registry that assesses long-term efficacy, safety, patient benefit, and treatment regimens of PsO. In addition, mean age and BMI among patients with psoriasis in this study were also lower than those in a study using a pool of PsoBest and SDNTT registry patients (47.6 years and $28.4 \mathrm{~kg} /$ $\mathrm{m}^{2}$, respectively) [19]. In our study, self-assessment of BSA revealed that $72 \%$ and $28 \%$ of patients in this study had moderate (BSA 3-10) and severe PsO (BSA > 10), comparable to other studies examining treatment goals among patients with PsO (mean Psoriasis Area and Severity Index (PASI) score of 14.5 indicating moderate to severe disease severity [5] and $53.5 \%$ of patients with moderate/severe disease in the Japanese study [20]. A higher percentage of patients were biologic-experienced, with $69.6 \%$ of the patients in this sample having any biologic experience. Interestingly, approximately $25 \%$ of patients reported $\mathrm{PsO}$ on the genitalia, consistent with other reports [18, 21-26].

Despite consisting primarily of patients with moderate disease, this patient population experienced a particularly high impact on QoL (as measured by DLQI) and symptom burden, including itch, skin pain, fatigue, and PSAB, a finding that is consistent with other studies $[5,19]$. While this study did not directly measure PsO severity using PASI, it did assess bothersomeness of current $\mathrm{PsO}$ symptoms using PSAB, which indicated great bothersomeness of current $\mathrm{PsO}$ symptoms with a mean score of 23.5 (out of 30 maximum). A greater percentage of patients with $\mathrm{PsO}$ in this study were observed to have PsA (48\%) compared to the study with pooled patients from PsoBest and SDNTT registries (19.1\%), as well as patients in the PsoBest registry $(22 \%)$ alone $[5,19]$. Furthermore, the patients in this study had considerable involvement of hard-to-treat areas (palms/soles, scalp, genitals), and QoL was found to be significantly impacted, with a mean DLQI score of 18.3 , which is higher compared to the studies from PsOBest and SDNTT (mean DLQI of 11.3) $[5,19]$.

In our study, patients placed high importance of a new treatment's overall efficacy and safety while considering a new treatment $(94 \%$ and $82.6 \%$, respectively), consistent with other studies wherein treatment efficacy was valued higher than the treatment safety among the patients $[15,27]$. At least $90 \%$ of patients valued "rapid response where you can see that the medication is clearing skin quickly", "keeping skin clear for 2-3 years", and "overall relief of symptoms (e.g., itching and skin pain)". Overall this data is consistent with previous reports (PsOBest and SDNTT) [5, 19].

On the basis of our knowledge, this is the first study to understand what "rapid" means in terms of treatment expectations, with patients reporting that approximately 2 weeks as an expectation for achieving a 50\% improvement in skin and approximately 4 weeks to achieve 
completely clear skin. There were certain numerical differences among the different subgroups analyzed, with younger age groups expecting response sooner than the older age groups and quite interestingly patients with moderate disease expecting a much faster response compared to patients with severe disease. Previous research has indicated that even residual disease can have a meaningful impact on QoL [28]. The data from this study may suggest that patients with moderate PsO who experience recurrence have a stronger desire to achieve clear skin more quickly compared to patients with severe $\mathrm{PsO}$.

One of the strengths of this study is the high number of respondents, the largest in the USA evaluating treatment goals among the patients. Additionally, the study did a comprehensive assessment of disease burden and also administered novel questions on treatment preferences, allowing for a comprehensive assessment of treatment goals and expectations. However, limitations should be noted and include the nature of the sample, as patients were recruited from an online panel, which may not be representative of the overall population of patients with PsO in the USA. This data may also not reflect the beliefs of patients who are not Caucasian or from countries other than the USA. There was also no comparison group in the study and the symptoms and severity levels were self-reported by the patients, which can lead to subjective responses leading to biased estimates. However, findings from this study provide insights for dermatologists into patient preferences toward treatment goals among patients who are unsatisfied with their current treatment and looking for a treatment change.

\section{CONCLUSIONS}

In this survey, patients with moderate to severe $\mathrm{PsO}$ who are on systemic therapies and are not satisfied with their current level of disease control place high value on treatment attributes related to efficacy with at least $90 \%$ of patients valuing clear skin, sustained response, and rapid onset of action. These patients had a very high disease burden and impact on QoL despite the majority of patients having only moderate disease. This data should provide valuable information to clinicians evaluating new treatment options for their patients who desire a treatment change or improved treatment outcomes. Considering these patient perspectives in treatment decisions is critical for optimizing patient outcomes.

\section{ACKNOWLEDGEMENTS}

We would like to acknowledge and thank all study participants.

Funding. This study and the Rapid Service Fee were funded by Eli Lilly and Company.

Medical Writing and/or Editorial Assistance. We would like to acknowledge Laura Clark, from Ipsos Insights LLC, for assistance with writing the manuscript. Funding for this assistance was provided by Eli Lilly and Company.

Authorship. All named authors meet the International Committee of Medical Journal Editors (ICMJE) criteria for authorship for this article, take responsibility for the integrity of the work, and have given their approval for this version to be published. All authors had full access to all the data in this study and take complete responsibility for the integrity of the data and accuracy of the data analysis.

Disclosures. Joe Gorelick has had a financial agreement or affiliation with the following commercial interests as a consultant for AbbVie Pharmaceuticals, Dermira, Lilly, LEO, Novartis Pharmaceuticals, Ortho Dermatologics, Pfizer, PruGen, Regeneron Pharmaceuticals, Sanofi Genzyme, Sun Pharma, and UCB; served on Advisory Board/Speaker's Bureau for AbbVie Pharmaceuticals, Dermira, Lilly, LEO Pharma, Novartis Pharmaceuticals, Ortho Dermatologics, Pfizer, PruGen, Regeneron Pharmaceuticals, Sun Pharma, and UCB. David Rosmarin has received honoraria as a consultant for AbbVie, Celgene, Dermavant, Dermira, Janssen, Lilly, 
Novartis, Pfizer, Regeneron, and Sanofi; has received research support from AbbVie, Bristol Meyers Squibb, Celgene, Dermira, Incyte, Janssen, Lilly, Merck, Novartis, Pfizer, and Regeneron Pharmaceuticals Inc; and has served as a paid speaker for AbbVie, Celgene, Janssen, Lilly, Novartis, Pfizer, Regeneron Pharmaceuticals Inc., and Sanofi. David Shrom is a current employee and shareholder of Eli Lilly and Company. Kiran Sikand is a current employee and shareholder of Eli Lilly and Company. Lisa Renda is a current employee and shareholder of Eli Lilly and Company. Russel Burge is a current employee and shareholder of Eli Lilly and Company. Craig Krebsbach is a current employee of Ipsos Insights LLC. Christine Dworkin was an employee of Ipsos Insights LLC at the time of the study. Chitra Karki was an employee of Ipsos Insights LLC at the time of the study. Ripsi P. Patel was an employee of Ipsos Insights LLC at the time of the study.

Compliance with Ethics Guidelines. The study (Protocol \#18-045418) was approved by Pearl IRB and met the standards of both FDA 21 CFR 56.104 and DHHS 45 CFR 46.101 regulations. Informed consent (ICF) was obtained from all participants prior to participating in the study. This study was conducted in full conformance with the Guidelines for GPP published by ISPE and the laws and regulations of the country in which the research was conducted.

Data Availability. The datasets analyzed during the current study are available from the corresponding author on reasonable request.

Open Access. This article is distributed under the terms of the Creative Commons Attribution-NonCommercial 4.0 International License (http://creativecommons.org/licenses/ by-nc/4.0/), which permits any noncommercial use, distribution, and reproduction in any medium, provided you give appropriate credit to the original author(s) and the source, provide a link to the Creative Commons license, and indicate if changes were made.

\section{REFERENCES}

1. Feldman SR, Regnier SA, Chirilov A, Hey F, Gilloteau I, Cella D. Patient-reported outcomes are important elements of psoriasis treatment decision making: a discrete choice experiment survey of dermatologists in the United States. J Am Acad Dermatol. 2019;80(6):150-1657.

2. Rachakonda TD, Schupp CW, Armstrong AW. Psoriasis prevalence among adults in the United States. J Am Acad Dermatol. 2014;70(3):512-6.

3. Mayo Clinic. Psoriasis overview. 2019. https://www. mayoclinic.org/diseases-conditions/psoriasis/sympt oms-causes/syc-20355840. Accessed 17 Oct 2019.

4. Menter A, Strober BE, Kaplan DH, et al, Siegel M, Wong EB, Wu JJ, Hariharan V. Joint AAD-NPF guidelines of care for the management and treatment of psoriasis with biologics. J Am Acad Dermatol. 2019;80(4):1029-72.

5. Blome C, Gosau R, Radtke MA, et al. Patient-relevant treatment goals in psoriasis. Arch Dermatol Res. 2016;308(2):69-78.

6. Bewley A, Burrage DM, Ersser SJ, Hansen M, Ward C. Identifying individual psychosocial and adherence support needs in patients with psoriasis: a multinational two-stage qualitative and quantitative study. J Eur Acad Dermatol Venereol. 2014;28(6):763-70.

7. Strober BE, van Der Walt JM, Armstrong AW, et al. Clinical goals and barriers to effective psoariasis care. Dermatol Ther (Heidelb). 2019;9(1):5-18.

8. Belinchón I, Rivera R, Blanch C, Comellas M, Lizán L. Adherence, satisfaction and preferences for treatment in patients with psoriasis in the European Union: a systematic review of the literature. Patient Prefer Adherence. 2016;10:2357-67.

9. Reich K, Mrowietz U, Radtke MA, et al. Drug safety of systemic treatments for psoriasis: results from the German Psoriasis Registry PsoBest. Arch Dermatol Res. 2015;307(10):875-83.

10. Maul J-T, Djamei V, Kolios AG, et al. Efficacy and survival of systemic psoriasis treatments: an analysis of the Swiss registry SDNTT. Dermatology. 2016;232(6):640-7.

11. Henseler T, Schmitt-Rau K. A comparison between BSA, PASI, PLASI and SAPASI as measures of disease severity and improvement by therapy in patients with psoriasis. Int J Dermatol. 2008;47:1019-23.

12. Naegli A, Zhu B, Gaich C, Heredia E, Song G. The Psoriasis Skin Appearance Bothersomeness (PSAB) 
measure for patients with moderate to severe plaque psoriasis. J Am Acad Dermatol. 2014;70(5):AB191.

13. Flytström I, Stenberg B, Svensson Å, Bergbrant IM. Patients' visual analogue scale: a useful method for assessing psoriasis severity. Acta Derm Venereol. 2012;92(4):347-8.

14. Reich A, Chatzigeorkidis E, Zeidler C, et al. Tailoring the cut-off values of the visual analogue scale and numeric rating scale in itch assessment. Acta Derm Venereol. 2017;97(6):759-60.

15. Kimball AB, Naegeli AN, Edson-Heredia E, et al. Psychometric properties of the itch numeric rating scale in patients with moderate-to-severe plaque psoriasis. Br J Dermatol. 2016;175(1):157-62.

16. Naegeli AN, Flood E, Tucker J, Devlen J, EdsonHeredia E. The worst itch numeric rating scale for patients with moderate to severe plaque psoriasis or psoriatic arthritis. Int J Dermatol. 2015;54(6): 715-22.

17. Finlay AY, Khan GK. Dermatology life quality index (DLQI) - a simple practical measure for routine clinical use. Clin Exp Dermatol. 1994;19:210-6.

18. Ryan C, Sadlier M, De Vol E, et al. Genital psoriasis is associated with significant impairment in quality of life and sexual functioning. J Am Acad Dermatol. 2015;72(6):978-83.

19. Maul JT, Navarini AA, Sommer R, et al. Gender and age significantly determine patient needs and treatment goals in psoriasis-a lesson for practice. J Eur Acad Dermatol Venereol. 2019;33(4):700-821.

20. Okubo Y, Tsuruta D, Tang AC, et al. Analysis of treatment goal alignment between Japanese psoriasis patients and their paired treating physicians. J Eur Acad Dermatol Venereol. 2018;32:606-14.
21. Meeuwis KAP, van de Kerkhof PCM, Dutronc Y, Henneges C, Kornberg LJ, Menter A. Prevalence of genital psoriasis in patients with psoriasis. J Dermatol Treatment. 2018;29(8):754-60.

22. Meeuwis KAP, de Hullu JA, Inthout J, et al. Genital psoriasis awareness program: physical and psychological care for patients with genital psoriasis. Acta Derm Venereol. 2015;95:211-6.

23. Zamirska A, Reich A, Berny-Moreno J, Salomon J, Szepietowski JC. Vulvar pruritus and burning sensation in women with psoriasis. Acta Derm Venereol. 2008;88(2):132-5.

24. van de Kerkhof PCM, De Hoop D, De Korte J, Cobelans SA, Kuipers MV. Patient compliance and disease management in the treatment of Psoriasis in the Netherlands. Dermatology. 2000;200:292-8.

25. Feman ML. The natural history of psoriasis in 5,600 patients. Dermatologica. 1974;148:1-18.

26. Cabete J, Torres T, Vilarinho T, Ferreira A, Selores M. Erectile dysfunction in psoriasis patients. Eur J Dermatol. 2014;24(4):482-6.

27. Alcusky MLS, Lau G, Chiu GR, Hadker N, Deshpande A, Fleming S, Vance N, Fakharzadeh S. Dermatologist and patient preferences in choosing treatments for moderate to severe Psoriasis. Dermatol Ther (Heidelb). 2017;7(4):463-83.

28. Takeshita J, Callis Duffin K, Shin DB, Krueger GG, Robertson AD, Troxel AB, Van Voorhees AS, Gelfand JM. Patient-reported outcomes for psoriasis patients with clear versus almost clear skin in the clinical setting. J Am Acad Dermatol. 2014;71(4): 633-41. 